\title{
A criatividade como expressão da subjetividade no envelhecimento
}

\section{Maria Cristina Reis Amendoeira}

Doutora (PhD) em Psiquiatria, Psicanálise e Saúde Mental pelo Instituto de Psiquiatria da Universidade Federal do Rio de Janeiro - UFRJ. Mestre em Psiquiatria, Psicanálise e Saúde Mental pela UFRJ (2001). Médica do Instituto de Psiquiatria da Universidade Federal do Rio de Janeiro, pesquisadora do Programa Organização do Trabalho e Saúde Mental de 2006 a 2016.

Psicanalista filiada à Sociedade Brasileira de Psicanálise do Rio de Janeiro, (SBPRJ, IPA). Membro da Associação Internacional de Psicanálise, IPA. Co-chair da América Latina do Comitê Perspectivas Psicanalíticas no Envelhecimento de Analistas e Pacientes, IPA - 2017.

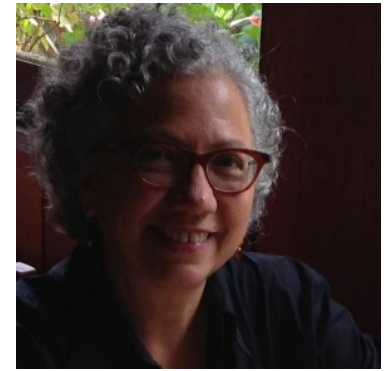

Dra. Maria Cristina Reis Amendoeira
$\Delta$ rte, envelhecimento e subjetividade são campos de estudo relacionados, já que o processo criativo e sua expressão na cultura são uma preocupação da psicanálise. Recentemente, o envelhecimento vem se tornando foco de vários estudos psicanalíticos, inclusive sob o aspecto da criatividade como recurso de manutenção da identidade no idoso.

Freud afirmou que a atividade artística, o consumo de obras de arte e a apreciação da beleza natural e da beleza artística são algumas das ações que podem proporcionar felicidade ao homem.

A arte lida com o princípio do prazer e com o princípio da realidade regulador de nossa aceitação das exigências sociais e culturais. Os sonhos e a criação artística também têm algo em comum ao buscar satisfazer desejos inconscientes. O fantasiar é um tipo de pensamento que não depende da presença de objetos no mundo real e que está presente na brincadeira das crianças e, mais tarde, no devaneio dos adultos.

A arte promove uma reconciliação desses dois princípios, o do prazer e o da realidade, por uma via peculiar. Originalmente, o artista é uma pessoa que, por não aceitar por completo a exigência de renúncia à satisfação pulsional, afasta-se dela e, no mundo da fantasia, dá livre curso a seus desejos eróticos e ambiciosos.

O psicanalista Fairbairn comparou arte e sonho. A função primária do sonho - fornecer meios de expressão para as necessidades reprimidas do sonhador provoca alívio na pressão dessas necessidades e reduz a tensão psíquica. No sonho não há atividade motora, e a realidade é a ilusão. Na obra de arte, que é construída pela atividade, há algo presente na realidade externa. A arte fornece um canal de expressão para as fantasias agressivas e cria um canal de expressão para fantasias de reparação.

Para Segal, a atividade artística estaria de tal modo relacionada às angústias depressivas e aos impulsos reparadores que se poderia considerar uma intenção de "recuperar e recriar" o objeto amado e "esse mundo perdido", como se dá no trabalho de luto com êxito, acompanhado de simbolização. Esses processos reparadores são transmitidos por meio da beleza formal, que representa o triunfo da reparação sobre a destruição. Segal atribui à fantasia inconsciente o papel 
de fonte para a arte criativa. As pulsões, desde o início da vida, dão origem à fantasia. O fantasiar é uma defesa contra realidades dolorosas e evolui com a experiência acumulada e o aprendizado com a realidade. A criação artística, por um tempo considerada como sublimação de desejos sexuais, avança para outro momento em que é relevante a presença das tendências destrutivas e conflitos narcísicos.

A expressão de uma subjetividade se dá na medida em que se cria e em que emerge a sensibilidade de artista. Para Freud, a habilidade do artista está na sua capacidade de ter acesso direto ao seu inconsciente. As imagens, então, em seus valores expressivos, são fonte de processos, de afetos, de significações. Porém, a imagem artística em especial tem uma inventividade nitidamente superior à de qualquer outra: ela permanece na esfera da descoberta; nos aproxima de um campo que é também o da psicanálise. É uma janela aberta da alma, que não depende de outra linguagem.

Outros psicanalistas contribuem com o tema, como Bion, que apresenta a arte como aprendizado e transformação, uma necessidade de busca pela verdade e liberdade do pensamento.

Mas, de que lugares em suas mentes, artistas criativos buscam material para a inspiração que é capaz de despertar emoções tão fortes em todos nós?

O campo da arte é terreno de sensibilidades e revela-se mais rico em termos de possibilidades do que o terreno cognitivo. As limitações, necessidades de mudanças e adaptações que surgem com o envelhecimento podem abrir novas possibilidades poéticas. Esse é o campo em que a limitação pode ser superada ou subvertida. Como exemplo, podemos citar Matisse, que, no final da vida, usou técnicas de recorte e colagem por conta de problemas motores.

Há diversos outros artistas que são exemplos de possibilidades de elaboração das perdas, como luto, processos de restauração e reparação no envelhecimento. Entre eles, Frida Kahlo, que, após um grave acidente na juventude, que a marcou por toda a vida, registrou em seu diário que sua "pintura traz em si a mensagem da dor. (...) Pintar completou minha vida".

A artista Louise Bourgeois, que procura elaborar seus traumas e expressá-los em obras de arte, fala da reparação utilizando conceitos psicanalíticos enunciados por Klein. A base da sublimação e da criatividade encontra-se na capacidade que cada um de nós tem de poder restaurar e recriar dentro de si objetos amados, antes percebidos como danificados. Assim como Freud, ela afirma que os artistas são capazes de acessar o inconsciente e expressam simbolicamente realizações psíquicas fundamentais.

A atividade artística permite transformação e crescimento, o que podemos considerar um tipo de restauração psíquica. A arte pode ser comparada à psicoterapia no que diz respeito à garantia de sanidade mental, pois, uma vez que ela se relaciona com as angústias depressivas e com impulsos reparadores, pode-se pensar nela como uma tentativa de recuperar e recriar um objeto amado dentro e fora e de si por parte do sujeito. Esse sentimento de ter o mundo interno destroçado leva todo artista a criar e recriar algo sentido como novo. A arte, então, pode ser considerada uma tentativa de resolução, uma necessidade de superar a depressão e o medo da morte, conforme Segal descreve em seu estudo sobre símbolos.

Então, assim como no trabalho de luto, a arte seria acompanhada de simbolização. E esses processos reparadores podem ser percebidos na beleza formal, que representa o triunfo da reparação sobre a destruição.

Ao envelhecer, deparamos com a possibilidade real de ruptura de vínculos e podemos ser envolvidos pela pulsão da morte - uma força de desligamento e destrutividade. Torna-se um desafio gerar ou manter projetos criativos e 
lidar com perdas de todo tipo. Duas direções se apresentam: o isolamento ou a possibilidade de elaborações criativas.

A criação artística, nesse momento da vida, pode ser concebida como atividade terapêutica, uma forma de contato do sujeito com suas emoções mais profundas. $O$ processo criativo traz em si alguma insatisfação: o desejo de alcançar beleza, equilíbrio ou expressão de um sentimento é real, mas não se pode prever o caminho que leva a esse resultado. Na criatividade está o valor da reconstrução, da recuperação de afetos perdidos e conflitos primitivos que podem ser revividos e remobilizados.

$O$ potencial terapêutico da arte requer a possibilidade de dar forma às emoções profundas, transformando-as e mudando-as de nível. A necessidade humana de criar e recriar a realidade busca na arte uma via de expressão da subjetividade e pode trazer alívio emocional.

As transformações da assistência no campo da saúde e da saúde mental, com ênfase na reabilitação, aproximam-se, na prática, da afirmativa da psiquiatra Nise da Silveira - pioneira na valorização da atividade expressiva, com o Museu de Imagens do Inconsciente - de que um ateliê de pintura deve ser um espaço em que possamos nos exprimir e nos relacionar com liberdade, procurando aceitar e entender o outro em sua forma de linguagem específica.

Nise da Silveira, nos anos 1940, inaugurou ateliês de pintura e modelagem para os clientes, em sua maioria esquizofrênicos, da seção de Terapêutica Ocupacional no Centro Psiquiátrico Nacional do Engenho de Dentro, no Rio de Janeiro, onde trabalhou de 1944 a 1975. Inconformada com os métodos de tratamento da época, a Dra. Nise buscava novas abordagens terapêuticas. Os pacientes trabalhavam regularmente, o que contribuiu para um crescente domínio da técnica pictórica. As pinturas foram realizadas sem orientação teórica e sem o conhecimento de reproduções de obras de arte. $\mathrm{O}$ monitor e artista, Almir Mavignier, procurava oferecer aos pacientes as melhores condições possíveis para que pudessem criar livremente, sem que nada os impedisse.

Mário Pedrosa, crítico de arte do jornal Correio da Manhã, demonstrou grande interesse sobre o assunto. Essa representação visionária do mundo não seria, para ele, exclusividade dos loucos, mas estaria presente em todo artista, em todo ser sensível. A transfiguração do mundo, por vezes mais fantasiosa, outras mais realista, é o próprio fazer artístico. A atividade artística, em sua forma mais viva e profunda manifesta o talento de cada um em sua afirmação da própria existência - o prazer estético libera tensões da vida psíquica, pensamentos, emoções e paixões. A criação artística recupera a dignidade do sujeito e o insere não em um mundo de velhos ou jovens, doentes ou sadios, mas em um campo social em que o trabalho criativo mantém todos na grande aventura de ser humano.

A vida da Dra. Nise é exemplo de criatividade, pois muitas de suas principais obras - sejam escritas, audiovisuais, exposições, eventos culturais ou grupos de estudo - aconteceram após a aposentadoria compulsória aos 70 anos. Ela produziu trabalhos e publicações até sua morte, aos 94 anos.

Outro exemplo é a psicanalista Marialzira Perestrello, que se manteve criativa até pouco antes de sua morte, em 2015. E, aos 91 anos, em plena produção intelectual, estudou o tema da criatividade e envelhecimento.

Os artistas do Museu de Imagens do Inconsciente também sofreram a passagem do tempo. $\mathrm{O}$ ateliê de pintura transformou-se num espaço de liberdade de expressão e de relacionamento ativo com o outro, de aceitação e entendimento da forma especial de linguagem para esses pacientes durante todas as suas vidas. Entre os artistas que surgiram das enfermarias e dos pátios do hospital e envelheceram no Centro Psiquiátrico Nacional, no Engenho de Dentro 
(atual Instituto Municipal de Assistência à Saúde Nise da Silveira), destacam-se Emygdio de Barros, Carlos Pertuis, Fernando Diniz e Adelina Gomes, que são exemplos da permanência da capacidade criativa no envelhecimento.

Mavignier afirma que, após anos afastado das atividades desses ateliês, ao visitar o Museu, deparou com as obras mais recentes dos clientes que acompanhara inicialmente e observou o aprimoramento técnico e a qualidade artística, apesar dos muitos anos de vida e internação.

Emygdio de Barros pintou até os 92 anos e foi considerado por Ferreira Gullar um dos raros gênios da pintura brasileira. Era carioca, e sua mãe sofria de um transtorno mental (as recordações a descrevem como vivendo isolada no quarto, excluída do convívio familiar). Ele também foi uma criança triste e muito tímida. Mas, já na infância, apresentava habilidades manuais especiais e construía caixas e brinquedos. Ao trabalhar no Arsenal da Marinha, foi designado para fazer um curso de aperfeiçoamento na França, onde permaneceu por dois anos. No retorno, passou a vagar pelas ruas, sem destino, a entrar nas igrejas, onde ficava horas de pé, imóvel e de olhos fixos. Logo foi levado ao Hospital da Praia Vermelha, em 1924, e em 1944 foi transferido para o Hospital do Engenho de Dentro.

Apesar dos longos anos de internação em condições adversas e sem nunca haver pintado antes, seu trabalho atingiu desde o início alto nível artístico, revelando talento incomum. Deixou um acervo de 3.300 obras. Envelhecido e doente, ao seguir para uma clínica geriátrica, a equipe levou material para que continuasse pintando, porém ele recusava-se e dizia: "O importante não é só pintar, é ter ideias para pintar. Aqui na clínica, não tenho ideias para pintar. Só no Museu. " A equipe mobilizou-se para que ele pudesse ir ao ateliê pelo menos duas vezes na semana, e assim ele voltou a pintar. Aos 92 anos, ao realizar aquele que seria o seu último trabalho, questionado por Nise da Silveira sobre seu significado, apontou a obra em azul e disse: "É o caminho para o infinito".

Carlos Pertuis, também carioca, com avós e pai franceses, foi o único varão entre três irmãs. Muito apegado à mãe e de frágil estrutura física e psicológica, tinha natureza sensível e religiosa. Abandonou os estudos na ocasião da morte do pai e passou a trabalhar numa fábrica de sapatos. A incidência dos raios do sol sobre o espelho em seu quarto surgiu diante de seus olhos como uma visão cósmica que descreveu como "O planetário de Deus". Foi internado no mesmo dia, em 1939, no Hospital da Praia Vermelha. Em 1946, ao saber que ele guardava seus desenhos em caixas de sapatos, na enfermaria, Almir Mavignier o encaminha ao ateliê. Pertuis pouco se expressava verbalmente, e o grande número de neologismos tornava ainda mais difícil a compreensão da sua linguagem.

Deixou um acervo de 21.500 obras. A última fase de seu trabalho, de alta qualidade estética, foi denominada por Mário Pedrosa de "A Longa Viagem". Essas obras são consideradas o auge da sua criação. Já envelhecido, troca pincéis e tinta a óleo pelo lápis-cera, e então surge uma série de desenhos com personagens seguindo em marcha para a eternidade.

Fernando Diniz, considerado o poeta do cotidiano, era baiano de Aratu, mulato, pobre, e nunca conheceu o pai. Chegou ao Rio de Janeiro aos 4 anos, com a mãe costureira. Morava em casas de cômodos e acompanhava sua mãe no trabalho, em casas de famílias ricas. Ele sonhava ser engenheiro. Apesar de inteligente e bom aluno, abandonou os estudos. Em 1944, ao nadar sem roupa em Copacabana, foi preso e encaminhado ao Manicômio Judiciário, sendo transferido em 1949 para o Engenho de Dentro. No ateliê ficava cabisbaixo e pouco se ouvia sua voz. Explicava a razão da beleza das suas pinturas: "Não sou eu, são as tintas". Seu trabalho abrange desde o figurativo ao abstrato, apresentando em sua composição tanto formas simples quanto estruturas complexas. 
Era um eterno aprendiz. Sua paixão pelos livros o deixava constantemente atualizado com os acontecimentos e descobertas científicas. $\bigcirc$ resultado gráfico dessa atividade é um caleidoscópio de imagens ora sucessivas, ora superpostas, dinâmicas e coloridas. Do espaço para o tempo, do inorgânico para o orgânico, do geométrico para o figurativo e vice-versa. Fernando vai tecendo seu universo. Seu interesse pelo movimento da imagem acaba por levá-lo a pintar e desenhar uma série inspirada pelo cinema, em que procura integrar, na imagem, o tempo e o espaço. O seu desenho animado "Estrela de Oito Pontas" (sob a orientação de Marcos Magalhães) foi premiado. É seu o depoimento: "Mudei para o mundo das imagens, mudou a alma para outra coisa. As imagens tomam a alma da gente". No Hospital Pedro Ernesto, da UERJ, muito doente, recolhia material de sucata e reciclava para utilizar criativamente. Realizou na ocasião uma incrível série em que o movimento era um dos seus interesses. Morreu aos 81 anos, deixando um acervo de 30 mil obras.

Adelina Gomes era uma moça pobre, tímida, filha de camponeses, que nasceu na cidade de Campos, Rio de Janeiro. Chegou a frequentar uma escola profissionalizante na qual aprendeu trabalhos manuais. Aos 18 anos, se apaixonou, mas sua mãe, a quem era muito apegada e submissa, não aceitou seu pretendente. Adelina tornou-se cada vez mais retraída, sendo internada em 1937, aos 21 anos, após estrangular a gata de estimação.

Almir Mavignier, em entrevista, conta: "Agressiva e perigosa, esta foi a descrição que recebemos dela e que nos aconselharia a não aceitá-la no ateliê. Interessado, porém, nas bonecas que ela fazia no hospital, fui buscá-la num dia chuvoso, protegendo-a com um guarda-chuva. Essa atenção tão normal naquelas circunstâncias deve ter contribuído para conquistar sua confiança". Apesar de sua atitude agressiva, negativista, não houve dificuldade para que aceitasse pintar quando começou a frequentar o ateliê, em 1946.

Inicialmente, dedicou-se ao trabalho em barro, modelando figuras que impressionam por sua semelhança com imagens datadas do período neolítico. Depois, na sua pintura, podem-se acompanhar as metamorfoses vegetais vivenciadas em seus delírios. Dedicou-se também à confecção de flores de papel. Adelina se tornou uma pessoa dócil e simpática, sempre concentrada em suas atividades. Diariamente visitava o Museu e pintava. Morreu aos 68 anos, em 21 de novembro de 1984, após agressão física por outra paciente, sem nunca ter saído do hospital. Deixou um acervo de 17.500 obras.

Outro artista a ser lembrado quando se fala de arte, permanência da criatividade e loucura é Arthur Bispo do Rosário, da Colônia Juliano Moreira, diagnosticado como esquizofrênico paranoide que, entre internações e altas, viveu cerca de 50 anos no manicômio. Produziu mais de mil peças com materiais que encontrava em seu cotidiano, como talheres e lençóis.

Pode-se afirmar que, na produção plástica desses artistas, não houve declínio da criatividade, como também não aconteceu com Chagal ou Picasso. As imagens, em seus valores expressivos, são fonte de processos, de afetos e de significações. A arte é uma necessidade para que o homem se torne capaz de conhecer e mudar o mundo. Dessa forma, a atividade expressiva pode ser uma saída criativa para a busca de um novo equilíbrio no envelhecimento.

A necessidade de reinventar a realidade existe em todos nós e, por meio da criatividade, tentamos buscar instintivamente o sentimento de ser um sujeito que pertence a uma determinada época e cultura. A arte é uma forma de comunicação e o prazer estético experimentado por cada um pode nos aproximar da experiência poética do artista. Essa atividade criativa torna-se um canal de expressão emocional, de comunicação para o sujeito que envelhece. A arte é mais que um meio de revelar a verdade, representando de forma 
concreta e figurada o que agita a alma humana, mas é a própria expressão dessa humanidade.

Por meio da criação de imagens, de sons, por meio da transformação de materiais em linguagem, nos tornamos capazes de compartilhar com os outros nossos medos e encantamentos. A relação com a atividade artística possibilita ao idoso assimilar novas representações em sua vida psíquica, experimentar um novo sentido de identidade e reatar contato com fontes internas de vitalidade.

Essas obras, quando apresentadas ao mundo, adquirem novos significados, tantos quanto possíveis, ao estabelecerem diversas ligações com a sociedade e o diálogo no campo artístico. Elas estarão, portanto, sujeitas a outros agenciamentos e interpretações. $\mathrm{O}$ conselho de Cézanne mantém-se atual: libertar a figura de qualquer narrativa e deixá-la tornar-se, ela própria, uma via da sensação. E tal emoção que é despertada em nós nos aproxima de um acontecimento novo.

As crises que atravessamos potencializam o trabalho criador e a possibilidade de elaboração dos acontecimentos, com a transformação desses momentos de crise em lições de vida. Consideramos o envelhecimento mais uma etapa do desenvolvimento psíquico, e uma atitude criativa permite ver e rever a experiência de vida, encarando-as por uma nova perspectiva. A criatividade e a criação resultam de um trabalho psíquico que, juntamente com o trabalho de luto, podem conduzir a novas realizações. Poderemos, assim, viver criativamente a passagem do tempo. 